\title{
Dissolved gas analysis of thermal faults in transformer liquids simulated using immersed heating method
}

DOI:

10.1109/TDEI.2018.007158

\section{Document Version}

Accepted author manuscript

Link to publication record in Manchester Research Explorer

\section{Citation for published version (APA):}

Wang, X. F., Wang, Z. D., Liu, Q., \& Dyer, P. (2018). Dissolved gas analysis of thermal faults in transformer liquids simulated using immersed heating method. IEEE Transactions on Dielectrics and Electrical Insulation, 25(5), 17491757. https://doi.org/10.1109/TDEl.2018.007158

\section{Published in:}

IEEE Transactions on Dielectrics and Electrical Insulation

\section{Citing this paper}

Please note that where the full-text provided on Manchester Research Explorer is the Author Accepted Manuscript or Proof version this may differ from the final Published version. If citing, it is advised that you check and use the publisher's definitive version.

\section{General rights}

Copyright and moral rights for the publications made accessible in the Research Explorer are retained by the authors and/or other copyright owners and it is a condition of accessing publications that users recognise and abide by the legal requirements associated with these rights.

\section{Takedown policy}

If you believe that this document breaches copyright please refer to the University of Manchester's Takedown Procedures [http://man.ac.uk/04Y6Bo] or contact uml.scholarlycommunications@manchester.ac.uk providing relevant details, so we can investigate your claim.

\section{OPEN ACCESS}




\title{
Dissolved Gas Analysis of Thermal Faults in Transformer Liquids Simulated using Immersed Heating Method
}

\author{
X.F. Wang, Z.D. Wang and Q. Liu \\ The University of Manchester \\ Manchester, M13 9PL, UK \\ P. Dyer \\ UK Power Networks \\ Crawley, RH10 0FL, UK
}

\begin{abstract}
Dissolved gas analysis (DGA) is considered as one of the most effective techniques to diagnose transformer incipient faults. With the increasing applications of alternative liquids in transformers, fault gas generation characteristics of the liquids were investigated in laboratory under simulated faults. Immersed heating method has been widely used to simulate thermal faults, of which the complete fault temperature range was hardly achieved. In this paper, pool boiling theory was introduced to explain the underlying reason that why the complete fault temperature range cannot be achieved using immersed heating method. There are three stages in pool boiling including natural convection region, nucleate boiling region and film boiling region. The Nukiyama temperature of a mineral oil was found to be $330^{\circ} \mathrm{C}$. This is the highest stable temperature achieved by the immersed heating method in $\mathrm{T} 2$ region, beyond which the heating element temperature is unstable and hence temperature measurement is unreliable. The Nukiyama temperature of an ester liquid was found to $b^{\circ} 390^{\circ} \mathrm{C}$, which is higher than that of the mineral oil due to its higher boiling point. The findings imply that the previously published T2 DGA results obtained using immersed heating method at reported temperatures beyond the Nukiyama temperature have likely been in T3 region near to the melting temperature of the heating element (normally higher than $\left.1000^{\circ} \mathrm{C}\right)$.

Index Terms - transformer, dissolved gas analysis, DGA, thermal fault, mineral oil, ester liquid, pool boiling, Nukiyama temperature
\end{abstract}

\section{INTRODUCTION}

DISSOLVED Gas Analysis (DGA) is considered as one of the most effective techniques to diagnose transformer incipient faults. At the early stage, fault diagnoses based on the gases observed after failures of mineral oil filled transformers were attempted in the 1920s [1]. By 1956, a detailed fault assessment methodology based on the free gas collected from Buchholz relay had been developed [1]. It was then realised that the slowly developing faults would also generate gases which would be mostly dissolved in the oil. In the 1970s, analysis of dissolved gas was applied in plant monitoring and supervision of suspected faulty plant [1]. Four major steps were suggested in a DGA process: oil sampling, dissolved gases extraction, gas analysis and results interpretation. DGA was then found effective in diagnosing and preventing transformer incipient faults $[2,3]$.

Manuscript received on 3 November 2017, in final form 20 June 2018, accepted 23 June 2018. Corresponding author: Z. Wang.
Normally, DGA focuses on transformer thermal and electrical faults $[4,5]$. Analysis on the fault types of a group of transformers indicated that the thermal faults took up nearly $80 \%$ of the number of total fault types [2]. Therefore, it is important to understand thermal fault characteristics of alternative transformer liquids. Thermal faults refer to transformer faults whose hotspot temperature could cause the insulation materials or metals thermally decompose. Thermal faults used to be classified into four levels in early version of IEC 60599 which were $<150^{\circ} \mathrm{C}, 150-300^{\circ} \mathrm{C}, 300-700^{\circ} \mathrm{C}$ and $>700^{\circ} \mathrm{C}$ [6]. In the latest version of IEC 60599 , thermal faults were classified into three levels: $\mathrm{T} 1\left(<300^{\circ} \mathrm{C}\right), \mathrm{T} 2(300-$ $\left.700^{\circ} \mathrm{C}\right)$ and $\mathrm{T} 3\left(>700^{\circ} \mathrm{C}\right)$ [7]. The latter classification is widely accepted in many diagnostic techniques, such as Roger's Ratio method, Duval Triangle method and IEC Ratio method [8]. The latest IEC 60599 also addressed an in-depth description of the thermal faults: thermal faults below $300^{\circ} \mathrm{C}$ (T1) were identified if paper has turned brownish; above $300^{\circ} \mathrm{C}$ and below $700^{\circ} \mathrm{C}$ (T2) if paper has carbonized; and above $700^{\circ} \mathrm{C}$ (T3) were proved by oil carbonization, metal coloration or fusion [7].

In the 1970s, the ratio between ethylene and acetylene was 
found capable of differentiating between thermal and electrical faults [4]. Starting from this concept, various DGA fault diagnostic methods were developed based on different gas ratios. In addition, Duval Triangle method was introduced as a graphic method based on percentage combination of three fault gases [9]. These diagnostic methods were all established on DGA data from transformers with actual faults. The DGA results of faulty equipment were collected and the fault types and severities were identified by visual inspections $[10,11]$.

A thermodynamic assessment of gas formation in faulty transformers was performed theoretically in [12]. In this model, the oil molecules involved were assumed to be totally decomposed and the decomposition products are in equilibrium under several defined reactions [12]. This work theoretically proved that the ratios of several fault gases would change with fault temperature increasing, which led to the development of Roger's ratio method. A more comprehensive thermodynamic study was published where all oil molecule reactions were taken into consideration including primary and secondary decompositions [13]. At the same period, gas generation at certain temperature of thermal faults was studied by analysis of oil decomposition products in pyrolyzer [14]. However, both the theoretical assessment and oil pyrolysis study found that the gas generation characteristics are slightly different from DGA data collected from faulty transformers. The reason might be that the thermal faults in transformers are more miscellaneous than theoretical analysis or pyrolysis study. In real transformers, the oil contains a wider range of saturated and unsaturated hydrocarbon molecules than those are assumed in the thermodynamic assessment. In addition, in transformer thermal faults, the temperature is likely to distribute with gradient rather than a pure hotspot temperature which is quite different from the pyrolysis study. Therefore, neither the theoretical thermodynamic assessment nor the experimental pyrolysis study could fully reflect the fault gas characteristics in real transformers.

In the past two decades, DGA experiments under laboratory simulated faults were conducted in order to investigate the gas generation characteristics of various transformer liquids under different types and levels of faults [15-18]. Immersed heating method was commonly used to generate thermal faults. However, it was reported that the complete temperature range of thermal faults is difficult to be achieved using the immersed heating method. For example, most immersed heating element in mineral oils could only generate thermal faults up to $400^{\circ} \mathrm{C}$ and a higher heating energy might lead to inhomogeneous temperature distribution or burnout of the heating element [16, 18].

In this paper, a thermal fault test system was established based on the immersed heating method. DGA of a mineral oil Gemini X and a synthetic ester liquid MIDEL7131 was carried out under different conditions. The underlying mechanism of using immersed heating method to simulate thermal faults is explained according to the pool boiling theory. The achievable temperature ranges using the immersed heating method for both the mineral oil and the ester liquid were quantified.

\section{EXPERIMENTAL DESCRIPTION}

\subsection{TEST SETUP}

A sketch of the DGA thermal fault test system is shown in Figure 1. A leakage-free test cell was manufactured with the lid having a $120^{\circ}$ reverse funnel shape for ejecting all the air bubbles when filling the oil. A SERVERON TM8 multi-gas on-line DGA analyzer was used to measure the dissolved gas content of the oil. The oil volume in the test system is 2.95 litres. The oil is sampled from the lower part of the test cell into the DGA analyzer and returned back through the upper part. In such oil circulation configuration, the free gas bubbles if there is any can be constrained at the top of the test cell and not pumped into the DGA analyzer. In addition, the oil flowing through the gas phase increases the rate of free gas being dissolved into oil.

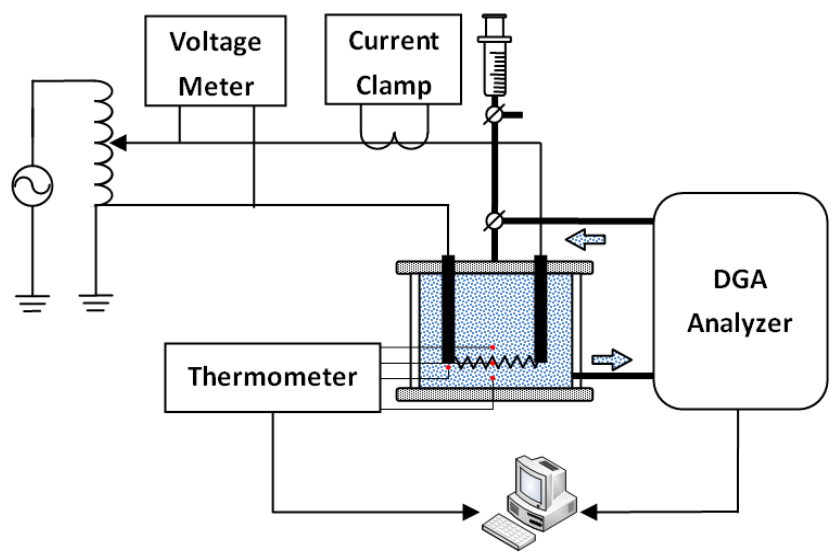

Figure 1. DGA thermal fault test system with immersed heating element.

The air bleeding pipe with a $50 \mathrm{~mL}$ syringe is connected to the top of the test cell via a three-way valve. The oil bleeding pipe and syringe have three major functions: 1) during oil filling process air can be pushed out through the bleeding pipe and the syringe can be used to replace air bubbles by oil in order to produce a pure oil system;2) during heating experiments the syringe works as an expansion vessel to relieve thermal expansion pressure of oil and maintain the whole system under atmosphere pressure; 3 ) oil can be sampled for laboratory measurements from the bleeding pipe.

Before filling the oil, the test system was pressurised with air to positive 100 mbar. Within 24 hours the positive pressure in the test system decreases to 84 mbar, which confirms the acceptable sealing condition.

The material of heating element is Kanthal A-1. It is alloyed with iron, aluminium and chromium which has higher resistivity and melting point $\left(1400^{\circ} \mathrm{C}\right)$ compared with normal copper wire heating element. The heating element is in a coil shape made by $0.6 \mathrm{~mm}$ wire. The size of the coil is $0.5 \mathrm{~cm}$ in diameter and $7 \mathrm{~cm}$ in length. A piece of ceramic thermocouple insulator was tightly inserted into the coil. A thermocouple was embedded in the ceramic insulator which measures the temperature of the heating element. Other thermocouples were located around the heating element to monitor temperature distribution around the heating element. 


\subsection{TEST PROCEDURE}

The experimental procedures are illustrated in Figure 2. Before heating, dissolved gas contents were measured by the TM8 on-line DGA monitor as the background gas level. Subsequently, the thermal fault was generated by injecting controlled input power into the heating element during the heating period. In the heating period, the oil expanded into the syringe. When reaching the capacity limit of the syringe, the heating needed to be ceased. The oil was mixed and cooled by circulation until the expanded oil flew back into the test cell, then the heating could be restarted. This was repeated until the total heating time reaches the designated fault duration. Finally, the gas contents were measured again with the TM8 on-line monitor as gas level after thermal fault. The absolute gas generation amount was calculated from the difference between the gas level after thermal fault and the background gas level. The whole procedures were repeated at another thermal fault level by varying the input power. In a T3 thermal fault, free gas was generated. It needs to be noticed that the free gas volume is measured by the syringe after T3 thermal fault in order to calculate the total gas amount.

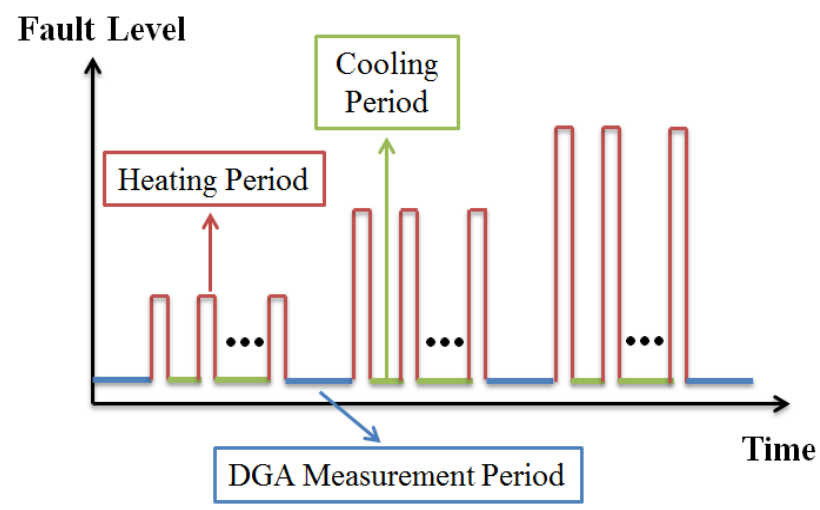

Figure 2. Experimental and measurement procedures.

In the first fault level (T1), the heating element is powered for about 8 minutes each time followed with 30 minutes cooling period. The total heating duration is 40 minutes after five cycles of heating and cooling. In the second fault level (intended T2), the heating time is about 3 minutes each time followed with 30 minutes cooling period. The total heating duration is 12 minutes after four heating and cooling cycles. In the third fault level (T3), heating duration each time is only about 8 to 10 seconds as considerable amount of gas bubbles are generated. The cooling period is still 30 minutes. The total duration for this simulated fault is about 30-50 seconds depending on whether the heating element is burnt or whether the free gas generation exceeds the syringe volume. In other words, the heating duration of T3 fault level is less controllable compared with $\mathrm{T} 1$ and $\mathrm{T} 2$.

Previous tests indicated that the fault gases in the system would reach quasi-equilibrium state three to five hours after the thermal fault [16]. This was based on the phenomenon that the detected gas concentration was usually increased in the initial two hours after the thermal fault and then reached a plateau. Therefore, the gas level after the thermal fault is calculated from the average of detection values during the plateau period.

\subsection{DGA MEASUREMENT}

The on-line DGA monitor used in this study detects fault gases with a laboratory graded GC system. It circulates the oil continuously at a flow rate of about $250 \mathrm{~mL}$ per minute. The oil flows through the extractor in which the dissolved gases are extracted from the oil. The gases are then sent into detector by carrier gas and analyzed.

To confirm the reliability of the DGA results measured by the on-line DGA monitor, the same oil samples were measured by a third-party professional oil analytical laboratory according to standardized procedures.

The on-line DGA monitor provides fault gas measurements with $\pm 5 \%$ accuracies. According to Round Robin tests over multiple laboratories, the reproducibility of conventional laboratory measurements with headspace method is $18 \%$ at medium gas concentration and $37 \%$ at low gas concentration [7]. Comparison between the on-line DGA and laboratory DGA measurements of oil samples used in this study is shown in Table 1.

Table 1 Comparison between laboratory and on-line DGA measurements in Gemini X oil sample, ppm

\begin{tabular}{|c|c|c|c|c|c|}
\hline T1 & $\begin{array}{c}\text { Lab DGA } \\
\text { Syringe 1 }\end{array}$ & $\begin{array}{c}\text { Lab DGA } \\
\text { Syringe 2 }\end{array}$ & $\begin{array}{c}\text { Lab DGA } \\
\text { Average }\end{array}$ & $\begin{array}{c}\text { On-line } \\
\text { DGA }\end{array}$ & D \\
\hline $\mathbf{C O}_{\mathbf{2}}$ & 353 & 327 & 340 & 318 & $\mathbf{- 6 \%}$ \\
\hline $\mathbf{C O}$ & 68 & 67 & 67.5 & 65 & $\mathbf{- 4 \%}$ \\
\hline $\mathbf{H}_{\mathbf{2}}$ & 0 & 0 & 0 & 0 & - \\
\hline $\mathbf{C H}_{\mathbf{4}}$ & 68 & 70 & 69 & 57 & $\mathbf{- 1 7 \%}$ \\
\hline $\mathbf{C}_{\mathbf{2}} \mathbf{H}_{\mathbf{6}}$ & 9 & 10 & 9.5 & 14 & $\begin{array}{c}\mathbf{4 . 5} \\
\mathbf{p p m}\end{array}$ \\
\hline $\mathbf{C}_{\mathbf{2}} \mathbf{H}_{\mathbf{4}}$ & 17 & 14 & 15.5 & 18 & $\mathbf{1 6 \%}$ \\
\hline $\mathbf{C}_{\mathbf{2}} \mathbf{H}_{\mathbf{2}}$ & 2 & 2 & 2 & 3 & $\begin{array}{c}\mathbf{1} \\
\mathbf{p p m}\end{array}$ \\
\hline \hline $\mathbf{T 3}_{2}$ & $\mathbf{L a b}$ DGA & Lab DGA & Lab DGA & On-line & $\mathbf{D}$ \\
\hline $\mathbf{C O}_{\mathbf{2}}$ & 456 & 449 & 452.5 & 458 & $\mathbf{1 \%}$ \\
\hline $\mathbf{C O}$ & 126 & 112 & 119 & 133 & $\mathbf{1 2 \%}$ \\
\hline $\mathbf{H}_{\mathbf{2}}$ & 1330 & 882 & 1106 & 922 & $\mathbf{- 1 7 \%}$ \\
\hline $\mathbf{C H}_{\mathbf{4}}$ & 1797 & 1578 & 1687.5 & 1555 & $\mathbf{- 8 \%}$ \\
\hline $\mathbf{C}_{\mathbf{2}} \mathbf{H}_{\mathbf{6}}$ & 291 & 261 & 276 & 277 & $\mathbf{0 \%}$ \\
\hline $\mathbf{C}_{\mathbf{2}} \mathbf{H}_{\mathbf{4}}$ & 2543 & 2290 & 2416.5 & 2129 & $\mathbf{- 1 2 \%}$ \\
\hline $\mathbf{C}_{\mathbf{2}} \mathbf{H}_{\mathbf{2}}$ & 129 & 121 & 125 & 118 & $\mathbf{- 6 \%}$ \\
\hline
\end{tabular}

There are two groups of DGA results compared in Table 1. The first group of the oil samples were obtained after a T1 fault and the second group of the oil samples were obtained after a T3 fault. The relative difference D is calculated as (On-line DGA - Lab DGA average) / (Lab DGA average). For ethane $\left(\mathrm{C}_{2} \mathrm{H}_{6}\right)$ and acetylene $\left(\mathrm{C}_{2} \mathrm{H}_{2}\right)$ in the $\mathrm{T} 1$ fault group, the absolute differences are provided due to the very low concentrations, which is an acceptable presentation [19].

The differences between the on-line monitor and laboratory measurements are within $\pm 20 \%$, which agrees 
with the observations reported for routine concentration levels in [19]. This confirms that the on-line DGA results in this work are reliable. In addition, adequate dissolved gas contents are necessary to mitigate the detection errors.

\subsection{GAS IN TOTAL CALCULATION}

In the sealed oil circulatory system, gas-in-total concentration of a certain type of gas can be calculated according to the detected gas-in-gas concentration in headspace and the gas/liquid phase volume ratio when the system reaches equilibrium state. Calculation method is shown in Equation (1)

$$
G I T=G I G \times[K(T)+\beta] \times P_{1} / P_{0} \times T_{0} / T_{1}
$$

where, the GIT and GIG are the gas-in-total and gas-in-gas concentrations in ppm, respectively; $K(T)$ is the Ostwald solubility coefficient at the extractor; $\beta$ is the volume (phase) ratio between gas phase and liquid phase; $T_{1}, P_{1}$ are temperature and pressure at the extractor in Kelvin and psi, respectively; $T_{0}, P_{0}$ are temperature and pressure under standard condition, i.e. $298 \mathrm{~K}$ and $14.7 \mathrm{psi}$, respectively $[20,21]$.

Either the relative gas amount (ppm) or the absolute gas amounts $(\mu \mathrm{L})$ are closely related to temperature and pressure. The dissolved gases measured by the on-line DGA monitor are extracted at operational extractor temperature and pressure and need to be converted to unified condition [20]. Hence, the unit of DGA is temperature and pressure dependent. There are commonly two temperature conditions of unit for DGA results, all of which are at standard atmosphere pressure: $0^{\circ} \mathrm{C}$ (STP) and $20^{\circ} \mathrm{C}$ (IEC) [19]. In this paper, the condition of unit of DGA results is $20^{\circ} \mathrm{C}$ (IEC).

\section{EXPERIMENTAL RESULTS}

\subsection{EXPERIMENTAL PHENOMENA}

At steady state, the heating element temperature is related to the input power. The relationship between heating element temperature and input power in Gemini $\mathrm{X}$ is shown in Figure 3.

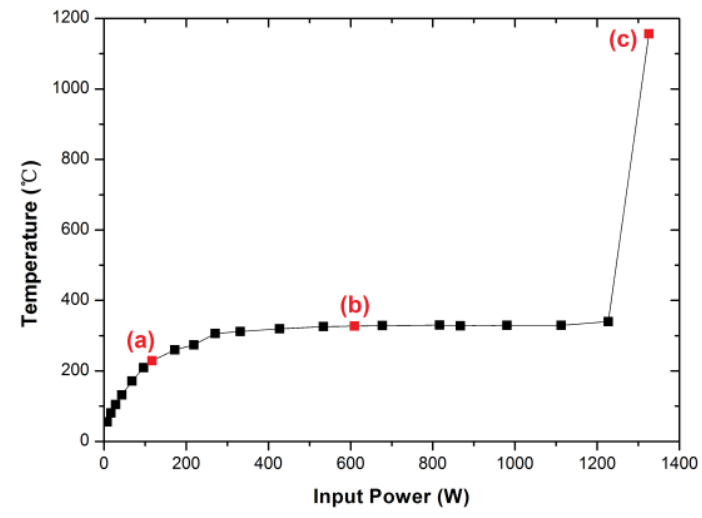

Figure 3. Relationship between heating element temperature and input power in Gemini X.
The heating element temperature increases with input power below $300 \mathrm{~W}$. However, it becomes stable or "saturated" above $300 \mathrm{~W}$ which remains in between $320^{\circ} \mathrm{C}$ and $330^{\circ} \mathrm{C}$. In this saturation region, the temperature cannot be increased even with a large increment of input power. If the input power keeps rising, e.g. approaching $1200 \mathrm{~W}$, the temperature along the heating element would suddenly become inhomogeneous and the hotspot temperature might reach higher than $1000^{\circ} \mathrm{C}$.

The experimental phenomena at different stages (a), (b) and (c) are shown in Figure 4, which correlate to the same legends marked on the heating element temperature curve in Figure 3.

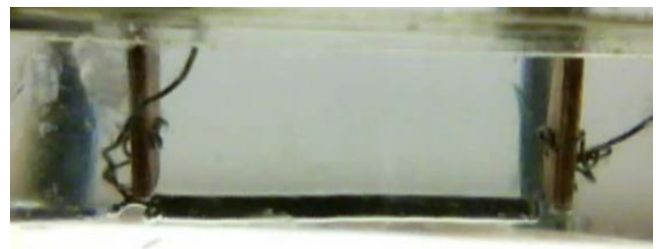

(a)

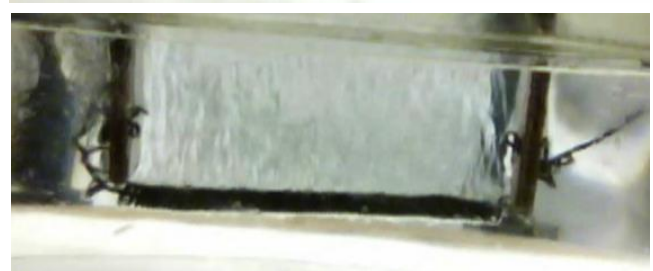

(b)

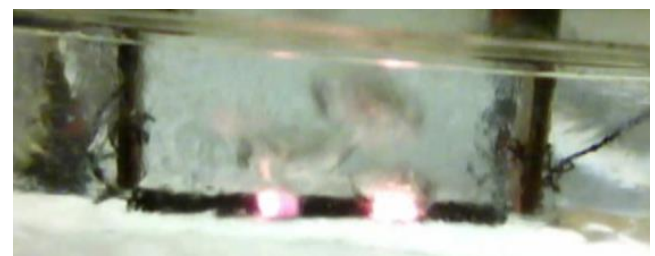

(c)

Figure 4. Experimental phenomena of thermal faults simulated with immersed heating element in Gemini X: (a) gentle convection; (b) strong convection and vaporization; (c) inhomogeneous heating.

When the input power is below $300 \mathrm{~W}$, the heating element temperature is lower than $300^{\circ} \mathrm{C}$. During the heating, there is only gentle convection observed near the heating element as shown in Figure 4a. With input power increasing into the "saturated" region, surrounding oil starts vaporizing and generates strong oil convection as shown in Figure 4b. At input power approaching $1200 \mathrm{~W}$, the heating becomes inhomogeneous. Some sections on the heating element emits visible light due to the radiation heat transfer where the pale yellowish color indicates the temperature is higher than $1000^{\circ} \mathrm{C}$ as shown in Figure 4c. In this case, a large amount of free gas bubbles are generated.

\subsection{POOL BOILING THEORY}

Pool boiling is defined as boiling from a heated surface submerged in a large volume of stagnant liquid [22]. The immersed heating in the DGA thermal fault experiments resembles a pool boiling process. The pool boiling theory can be explained by immersed heating in water as an 
example. The relationship between heating element surface heat flux and the heater surface temperature is defined as the "boiling curve". The boiling curve of heating in water is shown in Figure 5 [22]. There are in general four regimes on the boiling curve.

The first regime is natural convection region A-B where the heat energy is dissipated by water natural convection. The second regime is nucleate boiling region $\mathrm{B}-\mathrm{C}$ where the difference between temperature of heating element surface and water saturation temperature is sufficient to initialize vapor nucleation. As the vaporization normally absorbs large amount of energy, in this regime the surface heat flux increases rapidly but with minimal heat surface temperature increase. The point of critical heat flux (CHF) indicates the upper limit of nucleate boiling regime. The temperature at the CHF point is known as the Nukiyama temperature. The third regime is transition boiling region C-D. In this regime, the heater surface temperature exceeds the CHF point. The strong interaction between vapor stream and water around the heater restricts the adequate supply of subcooled water to dissipate the heating energy. Therefore, the heat dissipation efficiency starts to decrease. On the boiling curve, the temperature increases with surface heat flux decreasing. In the transition boiling region, the heater surface is covered by unstable vapor bubbles. The fourth region is film boiling region $\mathrm{D}-\mathrm{E}$. In this region, the heater is covered by a stable vapor film. The heat is transferred through the vapor film and it is dominated by radiation heat transfer. Therefore, the heater surface temperature would significantly increase with increasing surface heat flux. [22]

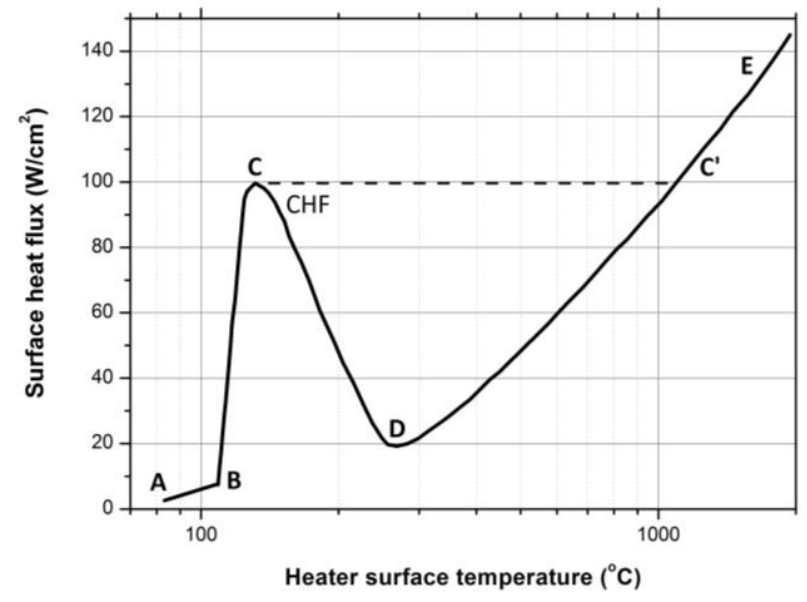

Figure 5. Pool boiling curve of water [22].

In practical situation, if the input power of heater is individually controlled, the heating process will follow the first and second regimes of the boiling curve, i.e. from A to C. Once it reaches the $\mathrm{CHF}$ point $\mathrm{C}$, the heater surface temperature is $35^{\circ} \mathrm{C}$ higher than the water saturation temperature. Any small increment of input power might cause a sudden jump of heater surface temperature to the point $C^{\prime}$. The $C^{\prime}$ is the next practical stable point after $C$. In other words, the boiling curve would jump from $C$ to $C^{\prime}$ and the transition boiling regime is actually missing. At the $\mathrm{C}^{\prime}$ point, the heater surface temperature is nearly $1150^{\circ} \mathrm{C}$. In many investigations of the boiling curves of water, heater failures are caused due to extreme high temperature at C' point which is also named as "burnout" $[22,23]$.

In summary the temperature range of transition boiling regime is "missing" in the immersed heating process. The upper limit of stable temperature is limited by the Nukiyama temperature at the critical heat flux (CHF) point which depends on the boiling point of the liquid. Beyond the $\mathrm{CHF}$ point, the heater temperature will suddenly jump to film boiling regime at temperature higher than $1000^{\circ} \mathrm{C}$ where most heaters might burnout. If the melting point of the heater is higher than the temperature at the C' point, the material could survive at this point e.g. as shown in Figure 4 (c). It should be noticed that the temperature distribution could be quite inhomogeneous in the practical film boiling regime.

\subsection{BOILING CURVE OF MINERAL OIL}

Boiling curve of the mineral oil used in this study Gemini $\mathrm{X}$ is tested and shown in Figure 6. It is plotted in the same format as the boiling curve of water shown in Figure 5.

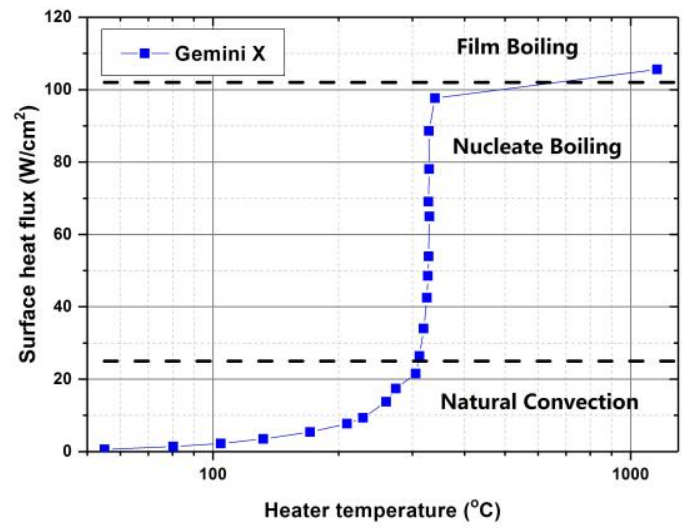

Figure 6. Pool boiling curve of Gemini $X$

When the input power is below $300 \mathrm{~W}\left(25 \mathrm{~W} / \mathrm{cm}^{2}\right)$, the boiling curve is in natural convection region where the heater temperature is below the oil boiling temperature. Once the input power is higher than $300 \mathrm{~W}$, nucleate boiling is initialized with vapor bubbles generated. In the nucleate boiling region, the heater surface temperature remains between $320^{\circ} \mathrm{C}$ and $330^{\circ} \mathrm{C}$ even with input power largely rising up. After the input power approaches $1200 \mathrm{~W}$ (102 $\mathrm{W} / \mathrm{cm}^{2}$ ), the heating becomes inhomogeneous as shown in Figure 4(c). This is in the film boiling region. Since the temperature is measured by thermocouple inserted in the centre of the heating element, it reflects the average temperature rather than surface hotspot temperature. Hence, the measured temperature in the film boiling region could not reflect the highest temperature. It was proved that the pool boiling phenomenon exists in immersed heating process in oil. In Gemini $\mathrm{X}$, the temperature in the nucleate boiling region is between $320^{\circ} \mathrm{C}$ and $330^{\circ} \mathrm{C}$. Then the temperature would suddenly jump to a temperature above $1000^{\circ} \mathrm{C}$ where the heating is inhomogeneous and the heating element is likely to burnout. 
In the nucleate boiling region, the heating element temperature is constant with a large increment of input power. The extra energy is dissipated by the vaporization as well as severer convection than in natural convection region. This was proved by the gas generation results shown in Figure 7. In this study, the heating element was heated to nucleate boiling region with three different input powers from 403 to $612 \mathrm{~W}$ where the input power increased by $50 \%$. However, the gas generation results are comparable. This proved that the increment of input energy did not increase the temperature of the heating element in the nucleate boiling region and hence not contribute to fault gas generations. The energy was dissipated through physical processes such as vaporization and convection.

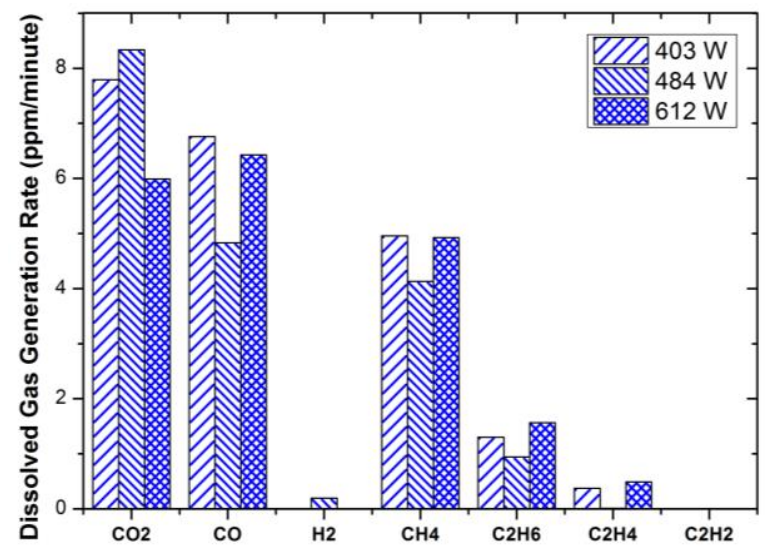

Figure 7. Gas generations from Gemini $\mathrm{X}$ in nucleate boiling region under different input powers.

\subsection{BOILING CURVE OF ESTER LIQUID}

In addition, the boiling curve of a synthetic ester MIDEL7131 was obtained and compared with that of the mineral oil as shown in Figure 8. In the natural convection region, the boiling curves of both liquids almost overlap with each other. In the nucleate boiling region, the heater surface temperature in MIDEL7131 is between 380 and $390^{\circ} \mathrm{C}$. In the film boiling region, the heating is inhomogeneous. The measured temperature might not reflect the highest surface temperature. When the Gemini X is heated to film boiling region, the measured temperature is higher than $1000^{\circ} \mathrm{C}$. This might be due to that red-hot zone is coincidentally near to the thermocouple location. In the MIDEL7131, the highest measured temperature is only about $410^{\circ} \mathrm{C}$. This is the case that the red-hot zone is not near to the thermocouple location. However, the film boiling region can be verified visually by the red-hot zone appeared on the heating element.

In the nucleate boiling region, the "saturated" temperature of heating element in MIDEL7131 is different from that of Gemini $X$. This might be due to the different boiling points. Gemini $\mathrm{X}$ is a type of naphthenic based mineral oil. Since the conventional mineral oil is a mixture of multiple types of hydrocarbon compounds, the boiling point is not a constant value. For Gemini $\mathrm{X}$, the boiling point is above $250^{\circ} \mathrm{C}$ [24].

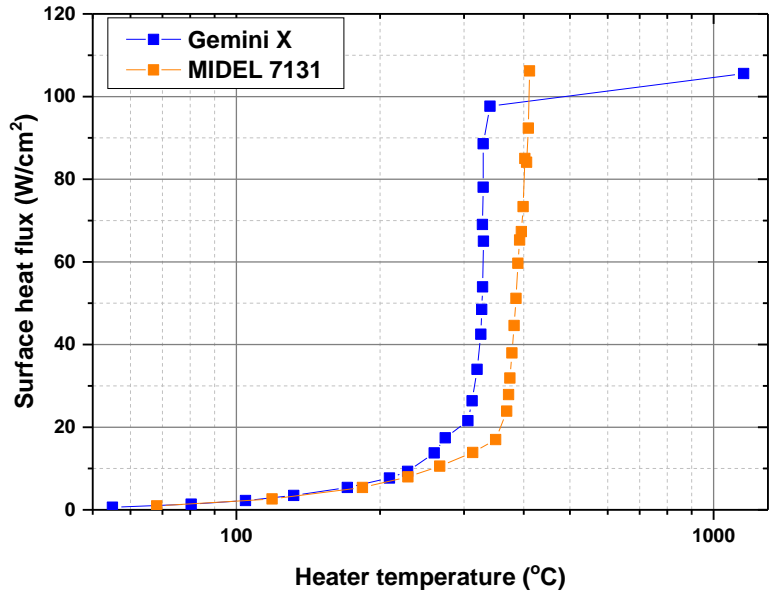

Figure 8. Pool boiling curve of Gemini X and MIDEL7131.

The highest temperature in the nucleate boiling region is known as Nukiyama temperature. The Nukiyama temperatures of a range of n-alkanes from pentane to hexadecane were investigated. They were found to be about $40^{\circ} \mathrm{C}$ higher than the boiling point [25]. Therefore, the temperature of heating element in the nucleate boiling region could be higher in the liquid with higher boiling point. The boiling point of MIDEL7131 is believed to be higher than that of Gemini $\mathrm{X}$. The results indicated that there is about $60^{\circ} \mathrm{C}$ difference between the Nukiyama temperature of Gemini X and MIDEL7131.

\subsection{DGA RESULTS IN NATURAL CONVECTION AND NUCLEATE BOILING REGIONS}

The total gas generation rates of both liquids in natural convection region averaged from three repeated tests are shown in Figure 9. The input power is about $200 \mathrm{~W}$. The total fault gas generation rates from Gemini $\mathrm{X}$ and MIDEL7131 are $318 \mathrm{ppm} / \mathrm{hour}$ and $267 \mathrm{ppm} / \mathrm{hour}$, respectively. It can be seen that the total gas generation rates in both liquids are comparable in natural convection region under the same fault energy. Methane $\left(\mathrm{CH}_{4}\right)$ is mostly generated from Gemini $\mathrm{X}$ as the major hydrocarbon gas. MIDEL7131 generates less hydrocarbon gases than Gemini $\mathrm{X}$ with ethane $\left(\mathrm{C}_{2} \mathrm{H}_{6}\right)$ as the major hydrocarbon gas.

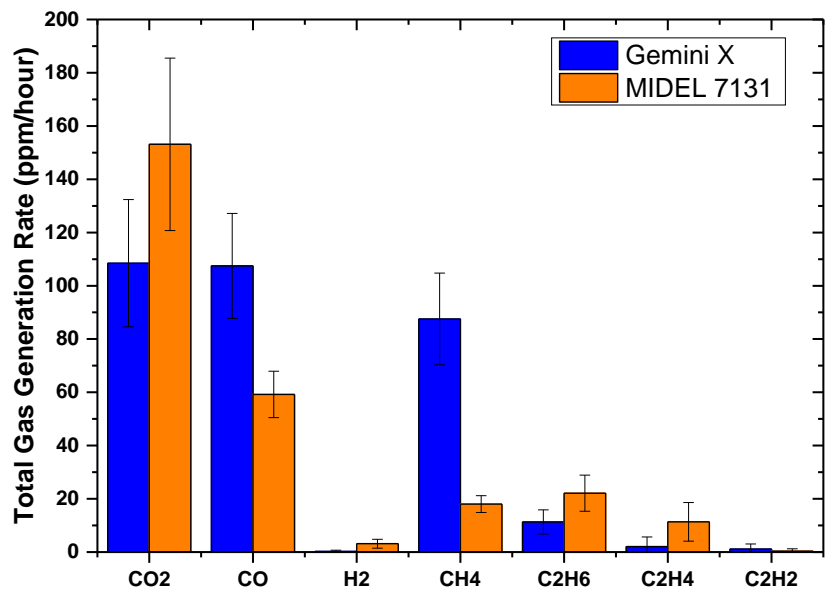

Figure 9. Total gas generation rates of Gemini $\mathrm{X}$ and MIDEL7131 in natural convection region. 
The total gas generation rates of both liquids in nucleate boiling region averaged from three repeated tests are shown in Figure 10.In this case, the generation rates of total fault gases and hydrocarbon fault gases from Gemini X are 1685 $\mathrm{ppm} /$ hour and $407 \mathrm{ppm} /$ hour, respectively. Those from MIDEL7131 are $4119 \mathrm{ppm} / \mathrm{hour}$ and $1780 \mathrm{ppm} / \mathrm{hour}$, respectively. Therefore, the total gas generation rates from MIDEL7131 are much higher than that from Gemini X with the similar input power. The major hydrocarbon gas for MIDEL7131 is ethane $\left(\mathrm{C}_{2} \mathrm{H}_{6}\right)$ while methane $\left(\mathrm{CH}_{4}\right)$ for Gemini X. In addition, MIDEL7131 generates more carbon oxides than the Gemini $\mathrm{X}$. The reason is that the heating element temperature in the nucleate boiling region is higher in liquids with higher boiling point, e.g. MIDEL7131. In other words, the fault gas generation could be different under the transformer thermal faults with similar fault energy if the oil is changed. For example, in this experiment, the thermal fault in Gemini $X$ in nucleate boiling region is closer to a T1 fault while T2 in MIDEL7131.

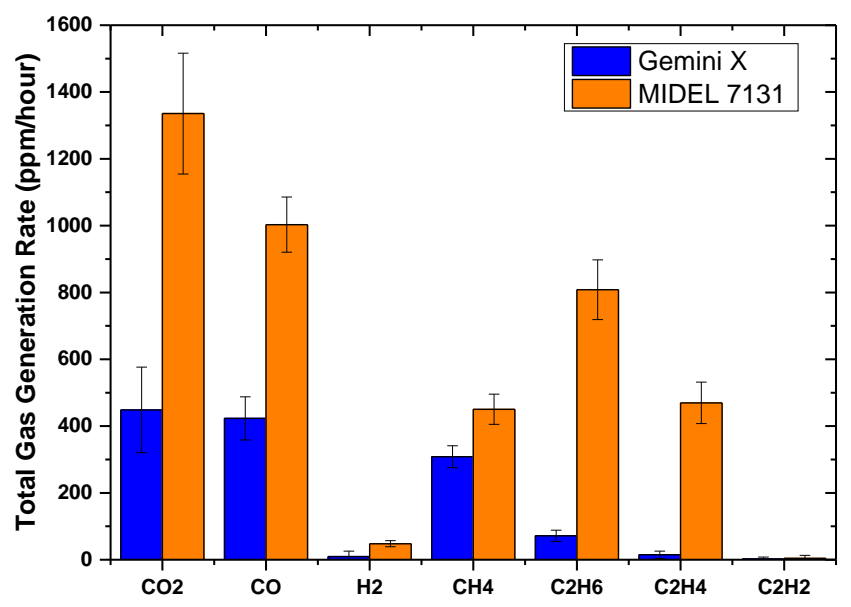

Figure 10. Total gas generation rates of Gemini $X$ and MIDEL7131 in nucleate boiling region.

\subsection{GAS GENERATION IN FILM BOILING REGION}

In the film boiling region, the input power is higher than $1200 \mathrm{~W}$. The total gas generation rates of Gemini $\mathrm{X}$ and MIDEL7131 averaged from three repeated tests are shown in Figure 11. In this situation, the temperature distribution along the heating element is quite nonuniform where the hotspot temperature could be higher than $1000^{\circ} \mathrm{C}$ with redhot phenomenon. The location and area of the red-hot are difficult to estimate, so the standard deviations of these results are larger than the results in natural convection and nucleate boiling regions.

According to the pool boiling theory, the burnout temperature is not relevant to the liquid properties in film boiling region. In Gemini $\mathrm{X}$, hydrogen $\left(\mathrm{H}_{2}\right)$ and hydrocarbon gases such as ethylene $\left(\mathrm{C}_{2} \mathrm{H}_{4}\right)$ and methane $\left(\mathrm{CH}_{4}\right)$ are largely generated. In MIDEL7131, the hydrocarbon gases are significantly less and carbon oxides are much more compared to the mineral oil. This indicated that the carbon oxides were generated from oil decomposition process of MIDEL7131 because there are considerable amount of oxygen atoms in the synthetic ester oil. Acetylene $\left(\mathrm{C}_{2} \mathrm{H}_{2}\right)$ as the key indicator of $\mathrm{T} 3$ thermal fault is generated in both liquids.

In the film boiling region, a large amount of free gas was generated. Therefore, it is noted that the reported hydrogen values could be underestimated because the hydrogen is difficult to be dissolved back into the oil when it is evolved into free gas in the present test setup.

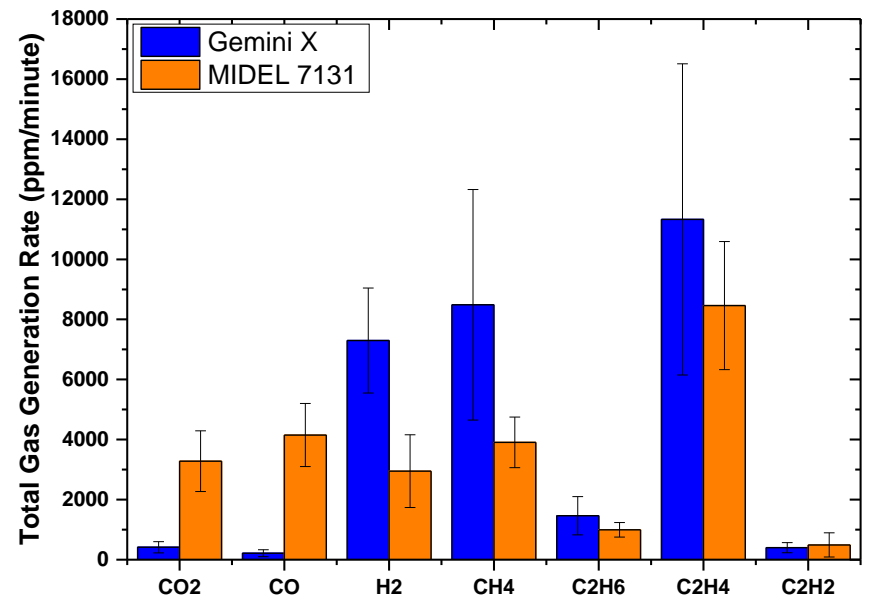

Figure 11. Total gas generation rates of Gemini $X$ and MIDEL7131 in film boiling region.

\section{PRACTICAL IMPLICATION}

The temperature of immersed heating element is limited by the pool boiling phenomenon. In conventional mineral oils, the boiling point is normally in the range of $250^{\circ} \mathrm{C}$ to $300^{\circ} \mathrm{C}$. The Nukiyama temperature is hence between $290^{\circ} \mathrm{C}$ and $340^{\circ} \mathrm{C}$. Once beyond this temperature, the heating would jump into the film boiling region where hotspot temperature is higher than $1000^{\circ} \mathrm{C}$. The complete temperature range of transformer thermal faults is hard to achieve with the immersed heating method. Therefore, previously reported $\mathrm{T} 2$ thermal fault results at the temperature above the Nukiyama temperature of the tested mineral oil based on immersed heating method $[16,18]$ might need to be re-interpreted.

The phenomenon that the heating wire was easily burnout and a large amount of free gases were evolved at $400^{\circ} \mathrm{C}$ in the DGA thermal experiment [16] could be explained as the heating element had already been in film boiling region and the measured temperature was not accurate. In other DGA thermal experiments, the fault gas generation at $400^{\circ} \mathrm{C}$ seems to be a T3 fault according to Duval triangle method where the percentage of methane, ethylene and acetylene is $38.7,51.4$, and $9.9 \%$, respectively [18]. This could also be due to the actual heating element surface temperature was much higher than the reported $400^{\circ} \mathrm{C}$. The actual fault temperature might be above $800^{\circ} \mathrm{C}$ due to the significant amount of acetylene generation [7]. In natural ester liquids, the stable heating element temperatures achieved were higher than that in mineral oils [16, 18]. It could also be explained by the pool boiling theory that the boiling point of the natural ester liquids is much higher than that of the mineral oils. 
Based on the pool boiling theory, the heating element would be in nucleate boiling region in a wide range of input powers. According to the previous discussions, the low boiling point of an insulating liquid limits the stable temperature achieved from immersed heating element in the nucleate boiling region. The immersed heating element in a liquid with higher boiling point can achieve higher stable temperature in the nucleate boiling region. This coincidently affects the temperature range that can be achieved in the so called T2 thermal faults $\left(300-700^{\circ} \mathrm{C}\right)$. Hence, it is necessary to measure the boiling curves of transformer liquids in order to know their Nukiyama temperatures and the range of thermal fault temperatures that can be achieved.

In addition, the boiling point of a liquid is relevant to the surrounding pressure. The Antoine equation is a semiempirical correlation which describes the relationship between vapor pressure and boiling temperature [26]. For example, the boiling point of hexadecane under an atmosphere pressure is $286^{\circ} \mathrm{C}$ while $320^{\circ} \mathrm{C}$ under a 2 bar absolute pressure. Therefore, if an immersed thermal fault in nucleate boiling region occurs at the bottom of the transformer, the temperature could be higher than that at the top due to the difference of surrounding oil pressures.

\section{CONCLUSION}

In this paper, the underlying mechanism of immersed heating thermal faults was discussed based on the pool boiling theory. In general, there are three regions of the heating process: natural convection, nucleate boiling and film boiling. In the natural convection region, the heating element temperature increases with input power increasing. In the nucleate boiling region, the heating element temperature is almost constant with input power increasing. The extra energy is dissipated by the vaporization and strong oil convection. Once the input power exceeds the critical heat flux (CHF) point, the temperature distribution along the heating element would become inhomogeneous and the hotspot temperature reaches the burnout temperature. Therefore, the immersed heating method could not reach temperature range between the Nukiyama temperature $\left(330^{\circ} \mathrm{C}\right.$ for the tested mineral oil and $390^{\circ} \mathrm{C}$ for the tested synthetic ester) and the burnout temperature (normally higher than $1000^{\circ} \mathrm{C}$ ).

The Nukiyama temperature depends on the boiling point of the liquid. The higher the boiling temperature, the higher the heating element temperature could reach in nucleate boiling region. Measurements of pool boiling curve including the Nukiyama temperature of various transformer liquids become necessary for interpreting DGA results of thermal faults using immersed heating methods.

\section{ACKNOWLEDGMENT}

The authors would like to express their gratitude to $M \& I$ Materials, National Grid, Scottish Power, Shell Global Solutions, TJ|H2b Analytical Services, UK Power Networks and WEIDMANN Electrical Technology for their financial and technical contributions to the transformer research consortium at The University of Manchester.

\section{REFERENCES}

[1] B. Barraclough, E. Bayley, I. Davies, K. Robinson, R.R. Rogera and C. Shanks, "CEGB experience of the analysis of dissolved gas in transformer oil for the detection of incipient faults", IEE Conference Publication, 1973, pp. 178-192.

[2] J. Kelly, "Predicting transformer incipient faults by dissolved gas in oil analysis", Electr. Insul. Conf, 1979, pp. 15-21.

[3] J. Rabaud, M. M. Thibault, J. Verdon and F. Viale, "Analysis of gases dissolved in oil and maintenance of transformers," Cigre Session, Paris, 1976, paper 12-06.

[4] B. Fallou, F. Viale, A. Devaus, R. Fournie, J. Galand, P. Vuarchex, I. Davies, R.R. Rogers, E.H. Reynolds and E. Dornenburg, "Application of physico-chemical methods of analysis to the study of deterioration in the insulation of electrical apparatus," Cigre Session, Paris, 1970, paper 15-07.

[5] IEEE Guide for the Interpretation of Gases Generated in OilImmersed Transformers, IEEE Std C57.104, 2008.

[6] Mineral oil-impregnated electrical equipment in service - Guide to the interpretation of dissolved and free gases analysis, IEC Std 60599,1978

[7] Mineral oil-impregnated electrical equipment in service — Guide to the interpretation of dissolved and free gases analysis, IEC Std 60599, 2016.

[8] N. A. Bakar, A. Abu-Siada, and S. Islam, "A review of dissolved gas analysis measurement and interpretation techniques," IEEE Electr. Insul. Mag., vol. 30, no. 3, pp. 39-49, 2014.

[9] M. Duval, "Dissolved gas analysis: It can save your transformer," IEEE Electr. Insul. Mag., vol. 5, no. 6, pp. 22-27, 1989.

[10] R. R. Rogers, "IEEE and IEC codes to interpret incipient faults in transformers, using gas in oil analysis," IEEE Trans. Electr. Insul., vol. EI-13, no.5, pp. 349-354, 1978.

[11] M. Duval, and A. DePabla, "Interpretation of gas-in-oil analysis using new IEC publication 60599 and IEC TC 10 databases," IEEE Electr. Insul. Mag., vol. 17, no. 2, pp. 31-41, 2001.

[12] W. D. Halstead, "A thermodynamic assessment of the formation of gaseous hydrocarbons in faulty transformers," J. of the Instit.of Petroleum, vol. 59, no. 569, pp. 239-41, 1973.

[13] M. Shirai, S. Shimoji, and T. Ishii, "Thermodynamic study on the thermal decomposition of insulating oil," IEEE Trans. Electr. Insul., vol. EI-12, no. 4, pp. 272-280, 1977.

[14] J. Galand, M. Thibault, F. Vide, J. Samat and P. Vuarchex, "Application de la chromatographie en phase gazeuse au diagnostic des dkgradations dans l'isolation des matkriaux Clectriques," Rev. Gen. Elect, vol. 81, paper 727, 1972.

[15] Z.D. Wang, X. Wang, X. Yi, S. Li and J.V. Hinshaw, "Gas generation in natural ester and mineral oil under partial discharge and sparking faults," IEEE Electr. Insul. Mag., vol. 29, no. 5, pp. 62-70, 2013.

[16] Z.D. Wang, X. Yi, J. Huang, J. V. Hinshaw and J. Noakhes, "Fault gas generation in natural-ester fluid under localized thermal faults," IEEE Electr. Insul. Mag., vol. 28, no. 6, pp. 45-56, 2012.

[17] H. Borsi, K. Durnke, and E. Gockenbach, "Relation between faults and generated gases in transformer liquids." in IEEE Int. Conf. Dielectr. Liquids (ICDL), 1999, pp. 487-490.

[18] M. Jovalekic, D. Vukovic, and S. Tenbohlen, "Dissolved gas analysis of alternative dielectric fluids under thermal and electrical stress." in IEEE Conf. Dielectr. Liquids (ICDL), 2014, pp. 1-4.

[19] Report on Gas Monitors for Oil-Filled Electrical Equipment, Cigre Brochure 409, 2010.

[20] Oil-filled electrical equipment - Sampling of gases and analysis of free and dissolved gases - Guidance, IEC Std 60567, 2011.

[21] Standard Test Method for Analysis of Gases Dissolved in Electrical Insulating Oil by Gas Chromatography, ASTM D3612-02, 2004.

[22] J. G. Collier and J. R. Thome, Convective boiling and condensation, Clarendon Press, 1994.

[23] S. Nukiyama, "The maximum and minimum values of the heat $Q$ transmitted from metal to boiling water under atmospheric pressure," International J. of Heat and Mass Transfer, vol. 9, no. 12, pp. 1419-1433, 1966. 
[24] Nytro Gemini X Safety Data Sheet, Nynas, 2006.

[25] A. Mills, and J. Fry, "Rate of evaporation of hydrocarbons from a hot surface: Nukiyama and Leidenfrost temperatures," European J. Phys., vol. 3, no. 3, pp. 152-154, 1982.

[26] W. Wagner, "New vapour pressure measurements for argon and nitrogen and a new method for establishing rational vapour pressure equations," Cryogenics, vol. 13, no. 8, pp. 470-482, 1973.

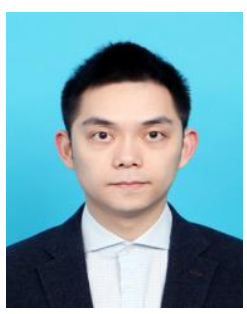

Xiongfei Wang received the B.Eng. degree from the Huazhong University of Science and Technology in 2012 and the M.Sc. and Ph.D. degrees in Electrical and Electronic Engineering from the University of Manchester in 2014 and 2017 respectively. Currently, he works for the State Grid International Development Co, Ltd. His research interests include Dissolved Gas Analysis of transformer insulating liquids, transformer condition monitoring and diagnosis, alternative transformer liquids and transformer asset management.

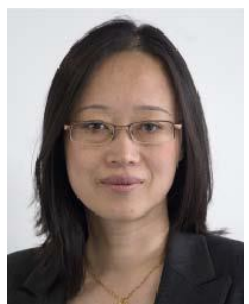

Zhongdong Wang received the B.Eng. and the M.Eng. degrees in high voltage engineering from the Tsinghua University of Beijing in 1991 and 1993 respectively and the Ph.D. degree in electrical engineering from UMIST in 1999. Currently, she is a Professor of High Voltage Engineering in the Power and Energy Division of the School of Electrical and Electronic Engineering at The University of Manchester. Her current research interests include transformer condition monitoring, transformer modelling, FRA, transients' simulation, insulation ageing and alternative insulation materials for transformers.

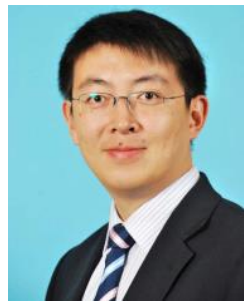

Qiang Liu (S'08-M'12-SM'18) obtained the B.Eng. degree in electrical engineering (2005) and the M.Eng degree in high voltage and electrical insulation (2008) from Xi'an Jiaotong University (XJTU) in China, and the Ph.D. degree in electrical power engineering (2011) from The University of Manchester in the UK. Currently, he is a Senior Lecturer in the Power and Energy Division in the School of Electrical and Electronic Engineering at The University of Manchester. His research interests are on pre-breakdown and breakdown phenomena in liquids, alternative transformer liquids, streaming electrification, ageing of insulating materials, thermal modelling, transformer asset management and high voltage testing.

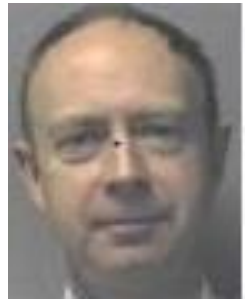

Paul Dyer joined the U.K. Electricity supply as a Student Apprentice with the London Electricity Board. After 5 years training he took up a position as a Commercial Engineer and from there moved to the System Operations branch. He has held various positions as an Engineer in the activities of London Electricity involving maintenance, operations, installation, and commissioning of low and high voltage electrical equipment. He moved to the Asset Management department and took up a position of Asset Performance Manager for London Electricity where he was responsible for the assessment of the performance of the Network equipment and making recommendations for its improvement. He then took up the position of Technical Manager responsible for the assessment and approval of the network equipment. He is now responsible for the specifications, assessment and approvals of transformers and Switchgear for UK Power Networks. Paul is a Chartered Electrical Engineer, Fellow of the Institution of Engineering and Technology, a Fellow of the Institution of Plant Engineers and a Fellow of the Society of Operations Engineers. 